\title{
Benign Endocrine Neoplasm
}

National Cancer Institute

\section{Source}

National Cancer Institute. Benign Endocrine Neoplasm. NCI Thesaurus. Code C4621.

A non-metastasizing, functioning or non-functioning neoplasm that arises from an

endocrine organ. Representative examples include thyroid gland follicular adenoma and parathyroid gland adenoma. 